\title{
Effect of Short Period Ground Motion on Seismic Design of Bridges and Viaducts
}

\author{
Yoshitaka MURONO, Dr. Eng. \\ Senior Researcher, \\ Kimitoshi SAKAI \\ Assistant Senior Researcher, \\ Earthquake \& Structural Engineering Laboratory, Structures Technology Division
}

\begin{abstract}
Recently earthquake ground motions with high frequency components have been observed on a regular basis. It is well known that the "effective input motion" is reduced in the high frequency range due to the effect of Kinematic interaction of the soil-pile system. Dynamic soil-pile interaction analyses, therefore, were conducted by varying the conditions of both the ground and piles, and the influence of input loss from the pile foundation was investigated. The result revealed that the input loss was negligibly small in case of ground motion whose amplitude was predominantly in the $1 \sim 2 \mathrm{~Hz}$ range, such as the Hyogoken Nanbu earthquake. On the other hand, the input loss was quite large in the case of high frequency seismic motion such as that observed in the Tohoku earthquake. A simplified expression of input loss, which could be used in practice for seismic design and is based on the Winkler-type spring model, was proposed.
\end{abstract}

Keywords: short period ground motion, kinematic interaction, input loss, effective input motion, seismic design

\section{Introduction}

Since the 1995 Hyogoken-Nanbu Earthquake, observation networks recording seismic ground motion such as " $\mathrm{K}$ NET" and "KiK-net" have been developed and large numbers of strong motion seismograms have been stored [1]. Strong motion seismograms that had shorter predominant period components and high peak accelerations were observed in both the 2003 Sanriku-Minami Earthquake and the 2008 Iwate-Miyagi Inland Earthquake. In the 2011 Earthquake off the Pacific Coast of Tohoku, seismic ground motion with peak values exceeding 1,000 (gal) were observed at 20 observation points. At the K-NET Tsukidate observation point, especially, intense motion of 3,000 (gal) was observed with a peak response acceleration of 5,000 (gal).

At the same time, design response acceleration spectra defined in design standards for railway facilities [2] or highway bridges [3] are envelopes of observed response spectra for periods over 0.5 seconds long, but do not cover the response spectra for shorter period ranges. The reasons for design ground motions not including envelopes of observed seismograms for shorter period ranges are based on the following engineering principles:

(i) natural periods for civil structures are $0.5 \sim 1.0 \mathrm{sec}-$ onds

(ii) dispersion damping is larger in the shorter period range

(iii) input motion can be reduced by "the input loss" caused by the kinematic interaction

However, it has not been verified whether these judgments are reasonable or not. Therefore, this paper, investigates the characteristics of short-period ground motion to clarify its effect on structural response from the view point of "soil-pile dynamic interaction" .

\section{Seismic ground motion with shorter periodic components}

Figure 1 shows examples of response spectra of short period earthquake ground motion during the recent earthquake which hit the Tohoku area. All this ground motion was observed on relatively firm ground, with a sedimentary layer thickness of less than $10 \mathrm{~m}$, and non-linear ground effects, therefore, were deemed to be relatively small. In this figure the design standard response spectrum of the L2 earthquake ground motion $[2,4]$ is also described. It should be noted that the response spectra of short-period earthquake motions significantly exceed the design response spectrum in shorter period ranges.

In order to discuss the reasons why the ground motion with shorter period components were generated, the depth from the ground surface to the seismic bedrock $(\mathrm{Vs}=3000 \mathrm{~m} /$ s) at observation points was investigated. Figure 2 shows the map of estimated depths to the seismic bedrock in Japan [5]. The figure clearly shows that short-period motion is generated in the area where the depth to the bedrock is generally shallower than $500 \mathrm{~m}$. The effects of short-period seismic motion on structural response are discussed in the next chapter.

\section{Evaluation of input loss by soil-pile interaction analysis}

\subsection{Formulation}

Piles, grouped beneath a superstructure, interact with the surrounding soil during an earthquake, and dynamic pile-soil-pile interaction often has a considerable knock-on effect to the motion of the superstructure. Some rigorous analytical methods have been developed to evaluate dynamic pile-soil-pile interaction [6]. Many railway viaducts 


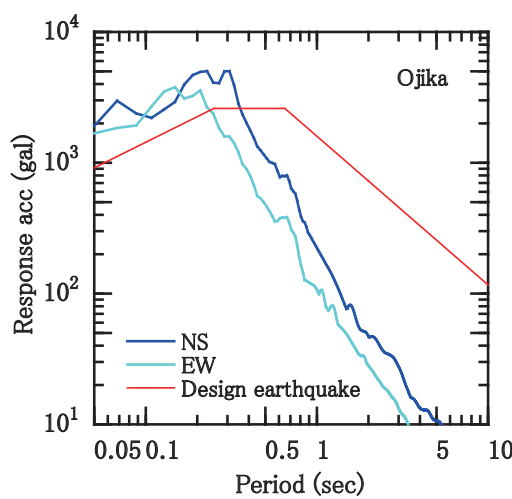

(a) Sanriku Earthquake

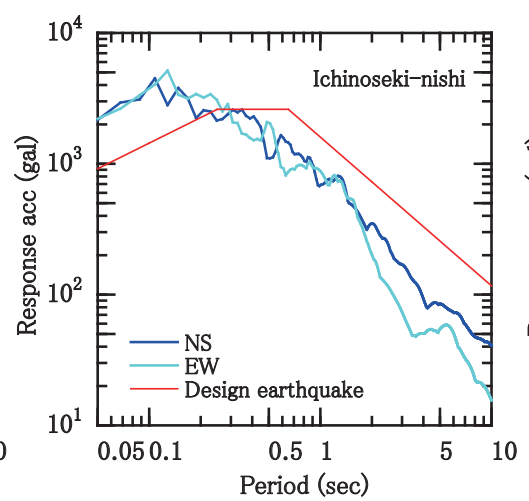

(b) Iwate-Miygi earthquake

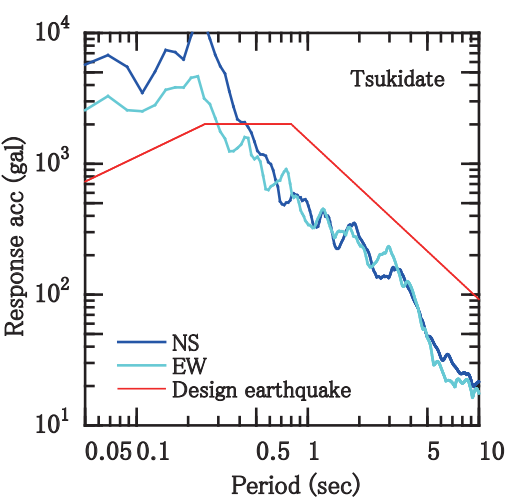

(c) Tohoku earthquake

Fig. 1 Examples of response spectra for short period earthquake ground motion during recent earthquakes

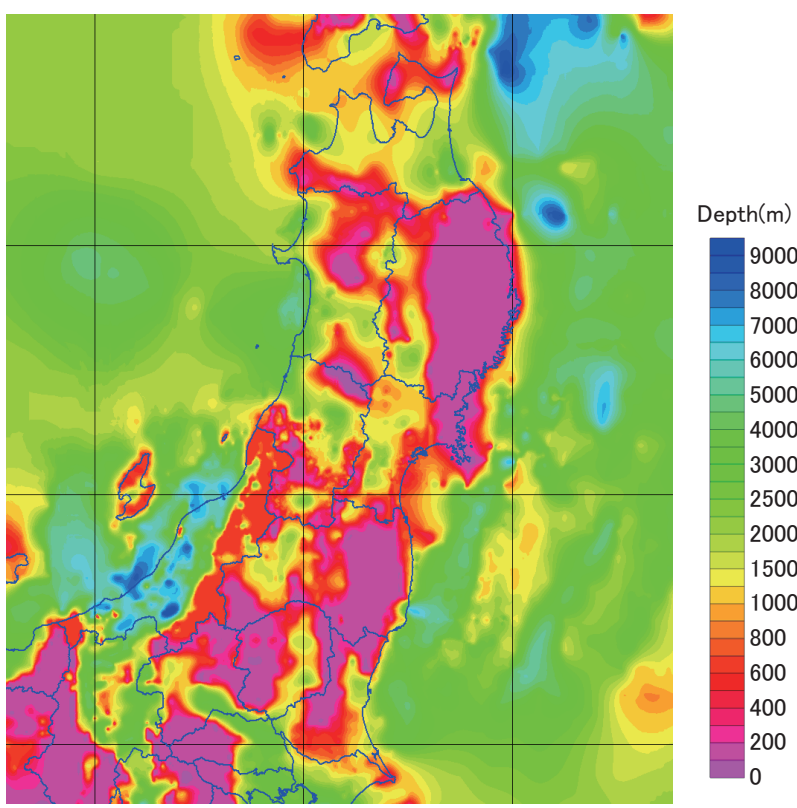

Fig. 2 Depth to seismic bedrock [5]

constructed in recent years, however, have only a few piles for one footing and their pile interval ratio $s / d$ is around 2.5. Under such conditions, it has been confirmed that the simplified method called "Equivalent Single Upright Beam Method" [7] could provide a good approximation. The method, therefore, was applied in this study.

A single upright beam is a composite of $n_{p}$ piles and soil enclosed together with them embedded in a horizontal stratified infinite soil deposit. The global equation of motion for the entire upright single beam is obtained as follows:

$$
\left(\left[\mathbf{F}_{H}\right]-\omega^{2}\left[\mathbf{M}_{H}\right]\right)\left[\begin{array}{l}
\left\{\mathbf{u}_{x}\right\} \\
\{\mathbf{w}\}
\end{array}\right]=\left[\begin{array}{l}
\left\{\mathbf{P}_{x}\right\} \\
\left\{\frac{\mathbf{M}_{y}}{R_{0}}\right\}
\end{array}\right]
$$

where $\left[\mathbf{F}_{H}\right]$ is the global stiffness matrix: $\left[\mathbf{M}_{H}\right]$, the mass matrix; and $\{\mathbf{P}\}=\left(\left\{\mathbf{P}_{x}\right\},\left(\mathbf{M}_{y} / R_{0}\right)^{T}\right)^{T}$, the external force vector. Now a foundation with a circular cross-section assumed to be embedded upright in the stratified soil will be examined. By using the "Thin Layer Method" assumption which gives semi-analytical solutions [8], the force-dis- placement relationship on the wall of the cylindrical hollow will be obtained as follows:

$$
\begin{aligned}
& {\left[\begin{array}{c}
\left\{\mathbf{P}_{\mathbf{x}}\right\} \\
\left.\left\{\begin{array}{l}
\mathbf{M}_{y} \\
R_{0}
\end{array}\right\}\right]=\left[\mathbf{R}_{H}\right]\left[\begin{array}{c}
\left\{\mathbf{v}_{\mathbf{r}}\right\} \\
\mathbf{r}
\end{array}\right\} \\
{\left[\mathbf{v}_{z}\right\}}
\end{array}\right.} \\
& {\left[\mathbf{R}_{H}\right]=\pi R_{0}\left[\mathbf{D}_{H}\right]\left[\mathbf{J}_{H}\right]^{-1}}
\end{aligned}
$$

where $\left\{\mathbf{v}_{r}\right\}$ and $\left\{\mathbf{v}_{z}\right\}$ are the displacement components on the wall. Finally, the equation of motion for the entire soilfoundation system is obtained by combining the equation for motion of the upright column (1) with the above equations $\left(\left\{\mathbf{v}_{r}\right\}=\left\{\mathbf{u}_{x}\right\}, \quad\left\{\mathbf{v}_{z}\right\}=\{\mathbf{w}\}\right)$ as follows:

$$
\left(\left[\mathbf{R}_{H}\right]+\left[\mathbf{F}_{H}\right]-\omega^{2}\left[\mathbf{M}_{H}\right]\right)\left[\begin{array}{l}
\left\{\mathbf{v}_{r}\right\} \\
\left\{\mathbf{v}_{z}\right\}
\end{array}\right]=\{\mathbf{P}\}
$$

It is assumed that a virtual soil foundation having the same size and shape as those of an actual foundation is embedded in the soil, and the response of the virtual soil foundation is obviously to be identical to the free-field ground motion. We now consider an actual foundation whose stiffness and mass are cut down by the quantities that offset this virtual soil foundation. This procedure leads to stiffness and mass matrices being modified as follows:

$$
\left[\mathbf{F}_{H}\right] \rightarrow\left[\mathbf{F}_{H}^{*}\right],\left[\mathbf{M}_{H}\right] \rightarrow\left[\mathbf{M}_{H}^{*}\right]
$$

The change in $\left[\mathbf{F}_{H}\right]$, however, turned out to be extremely small in many of the cases encountered, and can be ignored. Due to the existence of this foundation with $\left[\mathbf{F}_{H}\right]$ ( $\left[\mathbf{F}_{H}^{*}\right]$ correctly) and $\left[\mathbf{M}_{H}^{*}\right]$, the ground motion $\left\{\mathbf{v}_{r}\right\}$ at the soil-foundation interface deviates from the free-field ground motion $\left\{\mathbf{v}_{r}^{*}\right\}$, and the equation of motion is written in the following form,

$$
\left(\left[\mathbf{F}_{H}\right]-\omega^{2}\left[\mathbf{M}_{H}^{*}\right]\right)\left[\begin{array}{l}
\left\{\mathbf{v}_{r}\right\} \\
\left\{\mathbf{v}_{z}\right\}
\end{array}\right]=-\left[\mathbf{R}_{H}\right]\left(\left[\begin{array}{c}
\left\{\mathbf{v}_{r}\right\} \\
\left\{\mathbf{v}_{z}\right\}
\end{array}\right]-\left[\begin{array}{c}
\left\{\mathbf{v}_{r}^{*}\right\} \\
\{0\}
\end{array}\right]\right)
$$

which can be plotted as a function of frequency. The deformations of the foundation, $\left\{\mathbf{v}_{r}\right\}$ and $\left\{\mathbf{v}_{z}\right\}$, can be obtained by solving (4).

The ratio of the foundation motion, caused by the Kinematic interaction, to the free-field ground motion defined by (5) is called the "effective input motion factor" or the "kinematic displacement factor" . 


$$
\eta=\frac{v_{r, 1}^{*}+v_{r, 1}}{v_{r, 1}}
$$

The subscript " 1 " represents the first column for each vector $\left\{\mathbf{v}_{r}\right\}$ and $\left\{\mathbf{v}_{r}^{*}\right\}$. The index 1- $\eta$ is called the "input loss" and means the reduction from the free field ground motion. It is difficult to understand the characteristics of input loss directly from $\eta$ defined by (5), since $\eta$ is an imaginary number. In the following discussion, the kinematic displacement factor is rewritten by both the amplitude $|\eta|$ and phase angle $\phi$.

$$
\begin{aligned}
& |\eta|=\sqrt{\mathfrak{R}^{2}(\eta)+\mathfrak{I}^{2}(\eta)} \\
& \phi=\tan ^{-1}\left(\frac{\mathfrak{I}(\eta)}{\mathfrak{R}(\eta)}\right)
\end{aligned}
$$

\subsection{Analytical conditions}

A cast-in-place RC pile formed the object of this study. The pile was assumed to be supported at the pile-end and the pile head was assumed to be rigidly combined with the footing. From the use of the thin-layer element method, the analysis was restricted to treating the dynamic behavior of soil by linear assumption. In practice however soil behaves in a non-linear manner during L2 earthquake motion. Therefore, based on the concept of the equivalent linearization method, the value of the shear wave velocity $V_{s}$ used in the analysis was decreased from the initial value was defined for a quite small strain range. Also the value of the damping constant $h$ was set, taking account of the increment of damping which is caused by nonlinear hysteresis. Specifically, the shear wave velocity $V_{s}$ used for analysis was 0.75 times larger than the initial value $V_{s 0}$, and the damping constant $h$ was set to 0.10 . Table 1 shows the

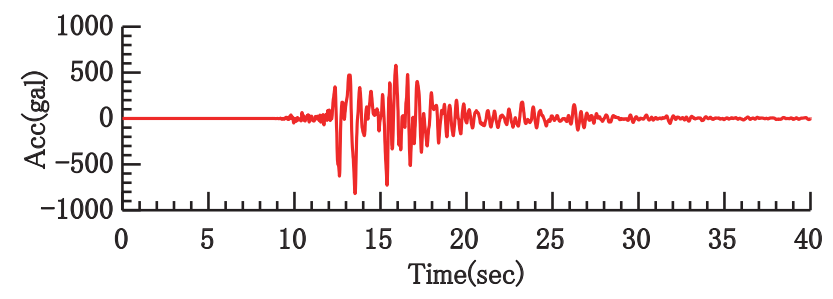

(a) Hyogoken-Nanbu earthquake (KOB wave)

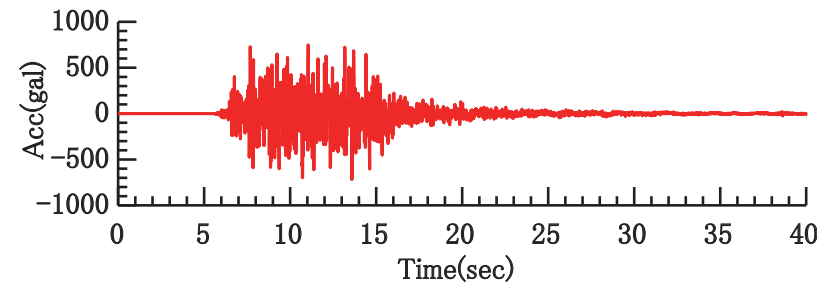

(b) Iwate-Miyagi earthquake (IWT wave)

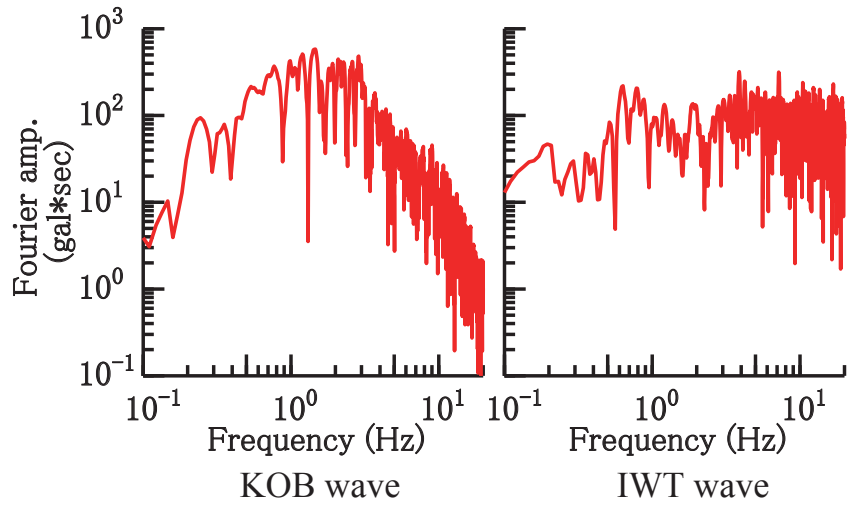

(c) Fourier spectrum

Fig. 3 Time histories and associated Fourier amplitudes

\begin{tabular}{|c|c|c|c|c|c|c|c|}
\hline & \multicolumn{4}{|c|}{ Parameters for pile } & \multicolumn{3}{|c|}{ Soil conditions } \\
\hline Case & $\begin{array}{c}\text { Diameter } \\
D(\mathrm{~m})\end{array}$ & $\begin{array}{c}\text { Pile interval } \\
\text { ratio } \\
s(\mathrm{~m})\end{array}$ & $\begin{array}{c}\text { Number of } \\
\text { piles }\end{array}$ & $\begin{array}{c}\text { Pile length } \\
l(\mathrm{~m})\end{array}$ & $\begin{array}{c}\text { Initial shear } \\
\text { wave } \\
\text { velocity } \\
\mathrm{V}_{\mathrm{s} 0}(\mathrm{~m} / \mathrm{s})\end{array}$ & $\begin{array}{c}\text { Poisson's } \\
\text { ratio } \\
v\end{array}$ & $\begin{array}{c}\text { Thickness } \\
H(\mathrm{~m})\end{array}$ \\
\hline $\begin{array}{r}2-1 \\
-2 \\
-3 \\
\end{array}$ & 1.0 & 3.0 & $2 \times 2$ & 15 & $\begin{array}{l}270 \\
200 \\
130\end{array}$ & 0.45 & 15 \\
\hline $\begin{array}{r}3-1 \\
-2 \\
-3 \\
\end{array}$ & 1.5 & 4.5 & $2 \times 2$ & 15 & $\begin{array}{l}270 \\
200 \\
130 \\
\end{array}$ & 0.45 & 15 \\
\hline $\begin{array}{r}4-1 \\
-2 \\
-3\end{array}$ & 1.0 & 3.0 & $2 \times 2$ & 10 & $\begin{array}{l}270 \\
200 \\
130\end{array}$ & 0.45 & 10 \\
\hline $\begin{array}{r}5-1 \\
-2 \\
-3\end{array}$ & 1.0 & 3.0 & $2 \times 2$ & 30 & $\begin{array}{l}270 \\
200 \\
130\end{array}$ & 0.45 & 30 \\
\hline $\begin{array}{r}6-1 \\
-2 \\
-3\end{array}$ & 1.0 & 3.0 & $3 \times 3$ & 15 & $\begin{array}{l}270 \\
200 \\
130\end{array}$ & 0.45 & 15 \\
\hline $\begin{array}{r}-1 \\
-2 \\
-3\end{array}$ & 1.0 & 3.0 & $4 \times 4$ & 15 & $\begin{array}{l}270 \\
200 \\
130\end{array}$ & 0.45 & 15 \\
\hline
\end{tabular}
of seismic ground motion used in this study

Table 1 Analyses conditions 


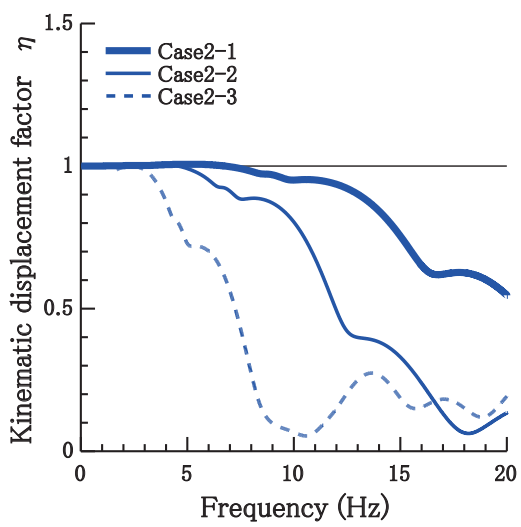

Case 2

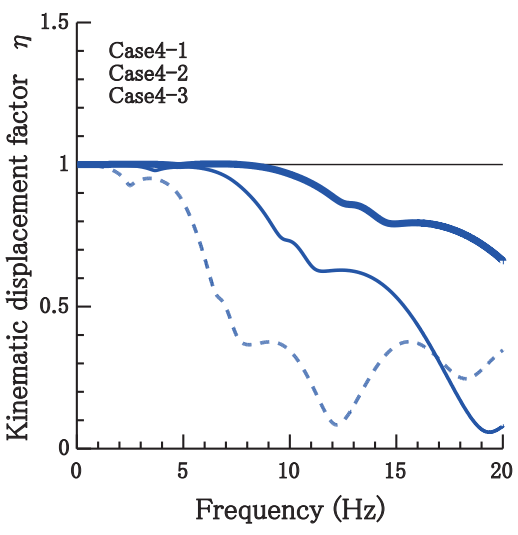

Case 5

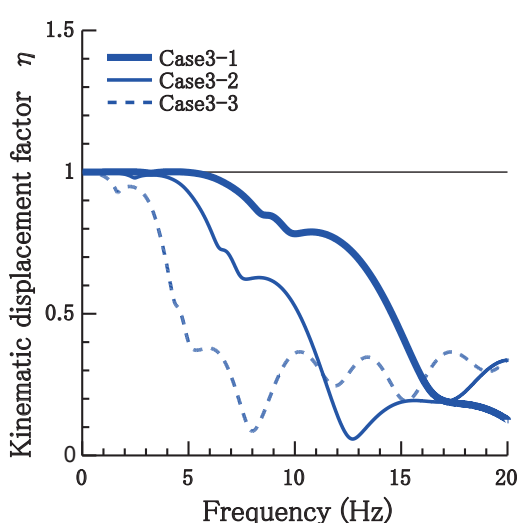

Case 3

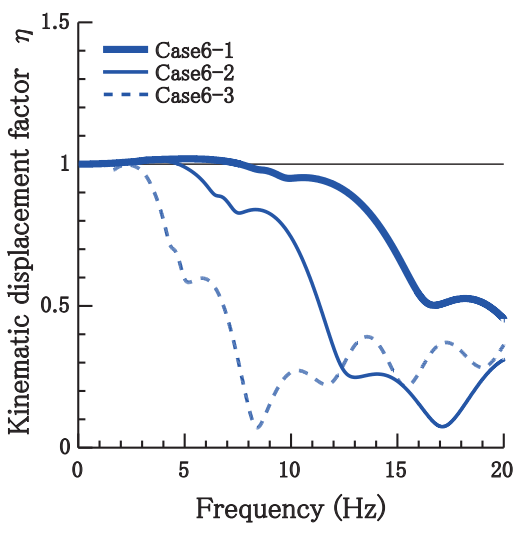

Case 6

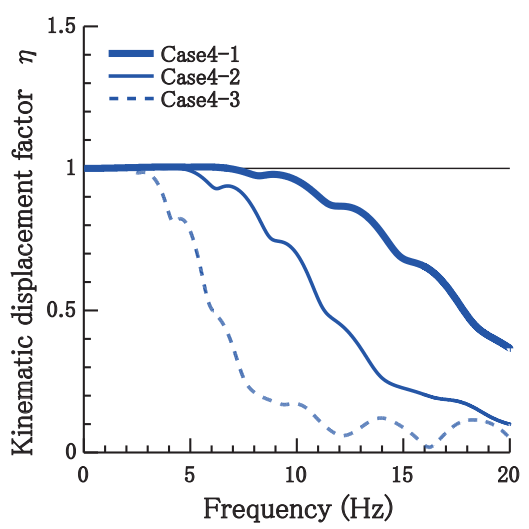

Case 4

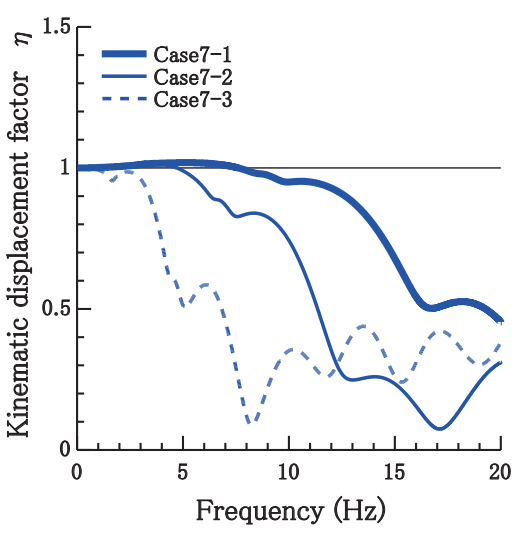

Case 7

Fig. 4 Amplitudes of the kinematic displacement factor $|\eta|$

conditions for analysis. In addition, assuming $\mathrm{RC}$ piles, the modulus of elasticity of the pile was set to $2.5 \times 10^{7}(\mathrm{kN} /$ $\mathrm{m}^{2}$ ).

Two types of seismic ground motion were used in the analysis. One was the seismogram observed at the Kobe JMA during the 1995 Kobe Earthquake (KOB wave), which is frequently referred to in design codes. Another was observed in Ichinoseki-Nishi during the 2008 Iwate-Miyagi Inland Earthquake (IWT wave), which contains a number of short period components. Figure 3 shows the acceleration time histories of the seismograms and their Fourier amplitude spectra. The predominant period of the KOB wave was around 1.0 ( $\mathrm{sec}$ ), which is close to the structural period of a bridge or viaduct. This was one of the underlying causes of the severe damage suffered by many civil structures. The IWT wave contains quite short period wave components and the predominant period is shorter than that of the KOB wave.

\subsection{Analytical results}

The amplitudes of the effective input motion factor (i.e. the Kinematic deformation factor) $|\eta|$ defined by eq. (6a) are calculated for all the cases shown in Table 1 and the results are shown in Fig.4. The mechanism of the input loss caused by the Kinematic interaction can be explained as follows: Since wavelengths in the higher frequency range become shorter in comparison with the pile length, a phase difference occurs in the behavior along the pile. As the result, pile restricts deformation of the free fields equalizing them. The factor $|\eta|$, therefore, is nearly equal to 1.0 in the low frequency range, but gradually decreases in the high frequency range due to input loss effect.

The characteristics of the kinematic displacement factor are strongly controlled by the pile diameter, pile length, number of piles and the relative stiffness of the ground to the pile. For example, comparison of cases 3 and 2 in Fig.4, show that the input loss grows as pile diameter increases or when the ground becomes softer. Comparison of cases 2, 5 and 4 illustrates that input loss also rises as the pile length becomes longer. Looking at cases 4, 2 and 5 together reveals that the input loss increases with the number of piles. In short, the relative stiffness of the foundation to the ground grows as pile diameter increases, the pile length becomes longer, or with the number of piles and when the ground is softer, which in turn provokes greater input loss.

Figure 5 shows the phase angle $\phi$ of the effective input motion. The phase angle increases as the frequency rises and becomes a positive value. This means that the input wave reaches the pile head faster than it reaches the ground surface. 


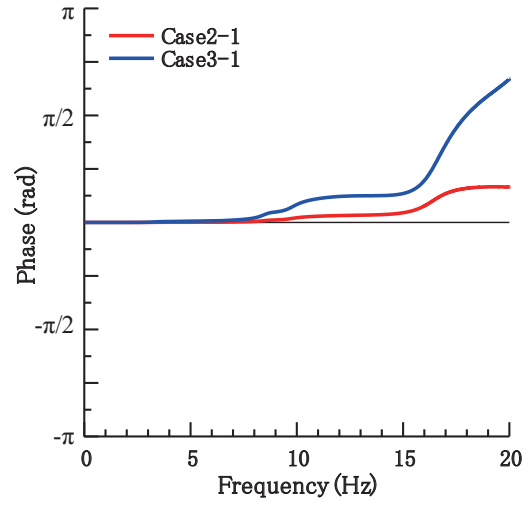

Fig. 5 Phase angles of kinematic displacement factors $\phi$

\subsection{Effects of input loss on the acceleration response spectrum}

This section examines the effect of input loss on structural response. At first, the effective input motion factor is multiplied into the Fourier amplitude of the seismogram of the free-field. The effective input motion is calculated from the inverse transformation of this modified Fourier amplitude. The response acceleration spectrum for effective input motion is also calculated. The results are shown in Fig.6. The effect of input loss was negligible for the Kobe Earthquake, which originally contained less highfrequency components. However, the effects of input loss

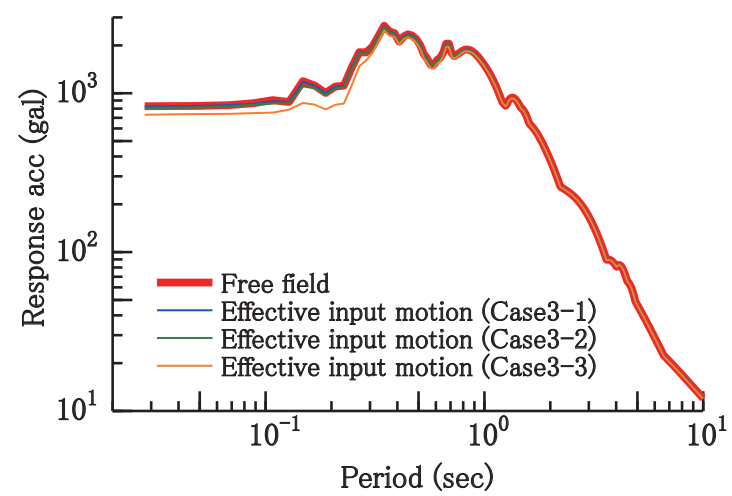

(a) KOB wave were quite obvious for the Iwate Inland Earthquake, which contained many high frequency wave components.

The seismic response spectra were then calculated for the seismic ground motion observed in the 2011 off the Pacific coast of Tohoku Earthquake by taking into account input loss effects. Figure 7 shows the results of response spectra. Even though the short-period seismograms with peak acceleration of more than 1,000 (gal) were recorded at more than 20 observation sites during the earthquake, the damage to civil engineering structures was limited but for damage by the tsunami. Some reasons explain this: (i) there has been ongoing seismic reinforcement of structures, (ii) the predominant period of the ground motion differed from that of the structure. Furthermore, it became evident that input loss reduced the power of the incident wave striking the structure as described above, which must have contributed to mitigating seismic damage to structures.

\section{Practical model of effective input coefficient}

\subsection{Approximate evaluation of effective input coef- ficient}

A simple calculation is demonstrated by using the "Beam Theory on Elastic Stratum", in order to understand the effects of input loss from pile foundations from the view point of design. The equation of motion for the beam on the elastic stratum is given by (7).

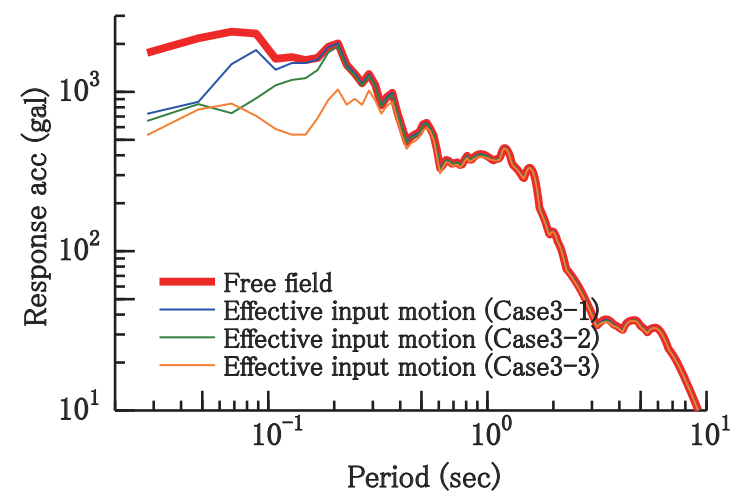

(b) IWT wave

Fig. 6 Response spectra of effective input motions
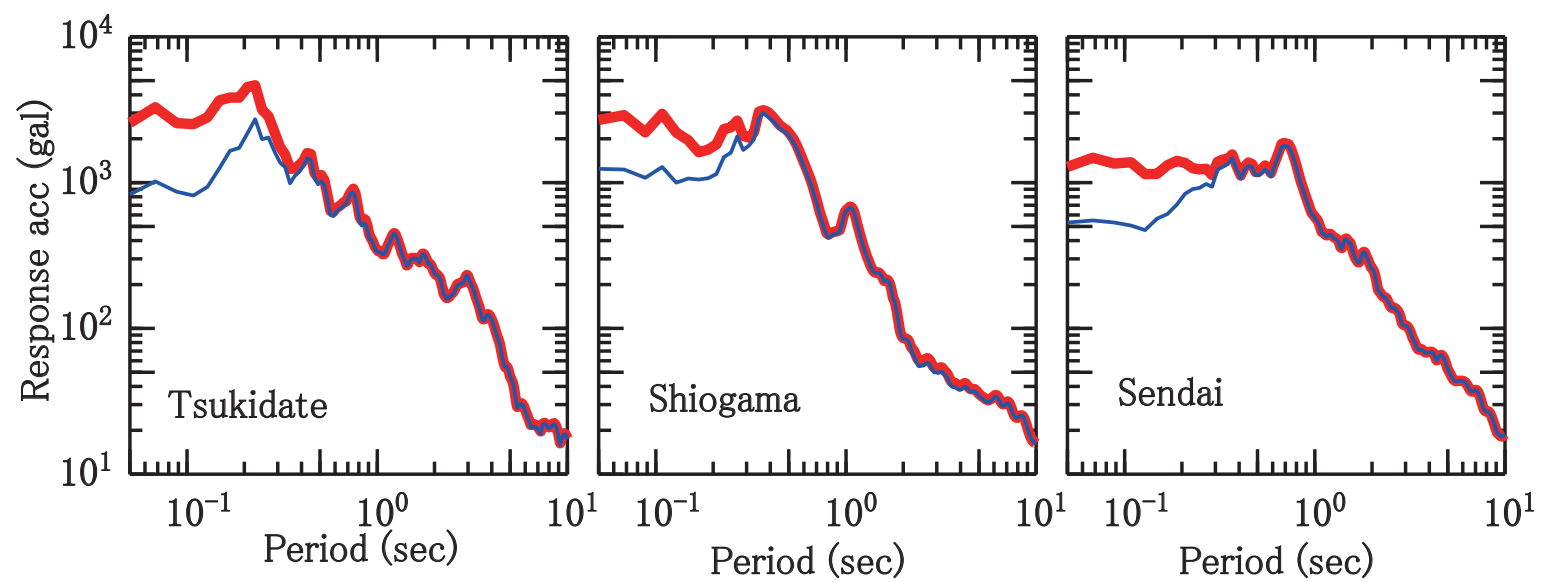

Fig. 7 Response spectra of effective input motions during Tohoku earthquake 

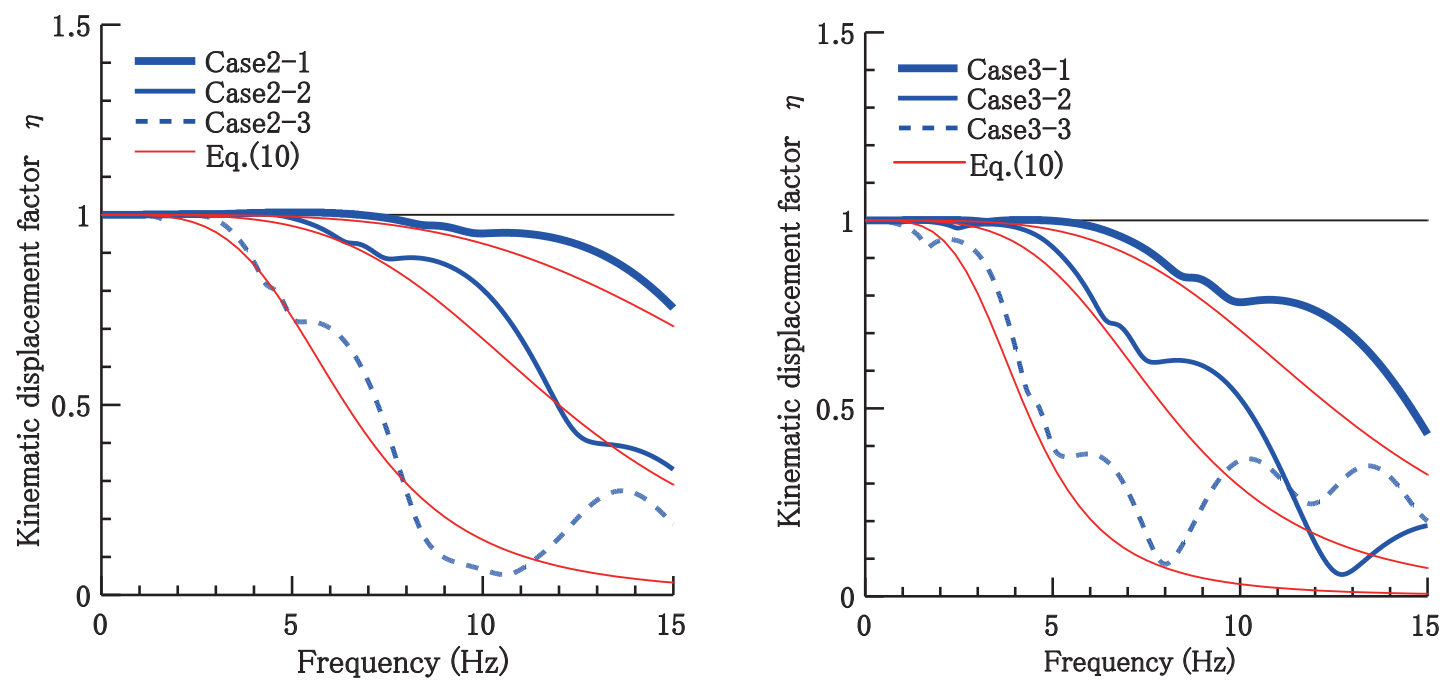

Fig. 8 Kinematic displacement factor

$$
E_{p} I_{p} \frac{\partial^{4} u}{\partial z^{4}}+k_{H} B\left(u-u_{g}\right)=-\rho_{p} A \frac{\partial^{2} u}{\partial t^{2}}
$$

where $E_{p} I_{p}$ is the bending stiffness of the pile; $\rho_{p}$, the density of the pile; $\mathrm{B}$, the loaded width; $\mathrm{A}$, the area of the cross section; and $k_{H}$, the modulus of the subgrade reaction. By adopting only particular solutions of (7) and also by ignoring the mass of the pile in accordance with the definition of effective input motion, the ratio of the displacement $U$ at pile head to the displacement at the ground surface $U_{g}$ is given by the following equation (8).

$$
\frac{U}{U_{g}}=\frac{1}{1+\frac{1}{4}\left(\frac{\omega}{\beta V S}\right)^{4}}
$$

where $\beta$ is the characteristic value of the pile. The index $U / U_{g}$ given by (8) can be said to be a simple expression of the Kinematic displacement factor $|\eta|$ defined in (6a). The compatibility of factor $U / U_{g}$ with $|\eta|$ was examined for each case. Vesic's expression was used for the modulus of the subgrade reaction $k_{H}$. Figure 8 shows an example of the results. The results from both were generally consistent in the frequency range of about $0(\mathrm{~Hz})$ to $10(\mathrm{~Hz})$. However, the correlation worsens for frequencies above $10(\mathrm{~Hz})$. The value $U / U_{g}$ converges to zero although the effective input factor $|\eta|$ obtained by the soil-pile dynamic interaction analysis has a lower limit. It can be said that a lower limit value at least is required when the approximate (8) is adopted.

\subsection{Proposal of a simplified model for the effective input coefficient}

A bearing pile foundation is generally used for a sedimentary layer whose thickness is 10 to $30(\mathrm{~m})$. In this case, the pile length $l$ is almost the same as the thickness of surface layer $H$. The shear velocity of the ground $V_{s}$ falls

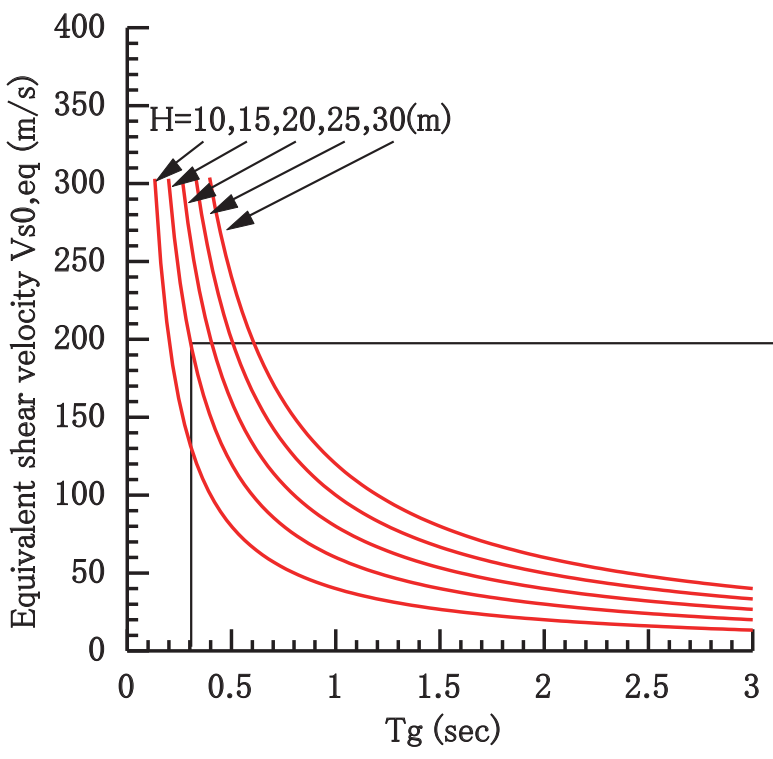

(a) Relation between $T_{g}$ and $V_{s 0, e q}$

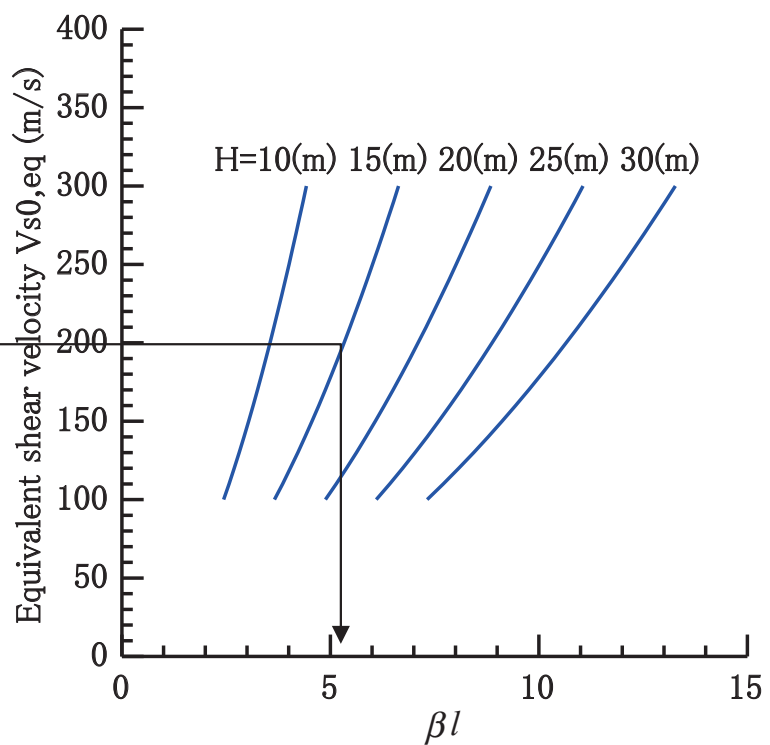

(b) Relation between $\beta l$ and $V_{s 0, e q}$

Fig. 9 Nomograph for calculating $V_{s 0, e q}$ and $\beta l$ 
according to its nonlinearity during an earthquake. The shear velocity, therefore, can be set as $V_{s}=\alpha \cdot V_{s 0}$, where $V_{s 0}$ is the initial shear velocity and $\alpha$ is a reduction factor. The natural period of the soil layer $T_{g}$ can be calculated by the following equation.

$$
T_{g}=4 \frac{H}{V_{S}}=4 \frac{H}{\left(\alpha \cdot V_{S 0}\right)}
$$

Substituting (9) into (8), the factor $U / U_{g}$ is rewritten as

$$
\frac{U}{U_{g}}=\frac{1}{1+\frac{1}{64}\left(\frac{\pi\left(T_{g} / \alpha\right)}{\beta l}\right)^{4} \cdot f^{4}}
$$

The factor $U / U_{g}$ defined in (10) is the practical expression of the effective motion factor $\eta$. The effective input motion can be calculated easily by using the newly proposed (10) without conducting soil-pile interaction analysis. As previously mentioned, however, a lower limit should be introduced in this formula since the value converges to zero as the frequency increases. The limit value is provisionally set to 0.4 .

Since an actual sedimentary layer consists of multiple layers, it is necessary to replace it with the equivalent single layer in order to use the proposed model in (10). At first, the equivalent shear velocity $V_{s 0, e q}$ is calculated by using Fig. 9(a), to make the natural period of the equivalent single layer ground equal to that of the actual ground. This figure illustrates the relationship between $T_{g}$ and $V_{s 0, e q}$ that is simply calculated from the "law of the quarter wavelength" . Next, the value $\beta l$ is calculated from Fig.9 (b) by using the equivalent shear velocity $V_{s 0, e q}$. The figure shows the relationship between $\beta l$ and $V_{s 0, e q}$. In preparing Fig.9 (b), the pile diameter $B$ was set to 1.0 , since the pile diameters constructed in recent years belong to the range of 1.0 to $1.5(\mathrm{~m})$. Substituting $\beta l$ and $T_{g}$ into (10), the equivalent input coefficient can be easily calculated.

\section{Conclusions}

Short-period ground motion has often been observed in recent earthquakes. The seismic response of structures against this type of motion is discussed from the view point of input loss caused by Kinematic interaction. A practical model for effective input loss has also been developed. The major conclusions are as follows:

(1) The relative stiffness of the pile increases when the diameter of the pile increases, the ground is softer, and the pile is shorter this leads to higher pile constraint on the behavior of the surrounding ground; loss of input motion rises, as a result.

(2) The effect of input loss is negligible for seismic ground motion whose predominant period is about $1 \sim 2(\mathrm{~Hz})$ such as that of the 1995 Hyogoken-Nanbu earthquake. In the case of shorter-period ground motion, observed in recent years however, the effects are not negligible.

(3) A practical model for the effective input factor was proposed to estimate the effect of input loss. Structures designed using this model are more resistant to short period earthquakes with intense acceleration.

\section{References}

[1] National Research Institute for Earth Science and Disaster Prevention, Strong-motion seismograph networks K-NET, KiK-net, http://www.kyoshin.bosai. go.jp/kyoshin/

[2] Railway Technical Research Institute, The Design Standards for Railway Structures and Commentary (Seismic Design), supervised by Ministry of Land, Infrastructure and Transport, Edited by., 2012 (in Japanese).

[3] Japan Road Association, Specifications for highway bridges V, Seismic Design, 2014 (in Japanese).

[4] Sakai K., Murono Y. and Sato T. "Evaluation of the level 2 earthquake motion by using recent earthquake," RTRI report, Vol.25, No.9, pp.5-13, 2011 (in Japanese).

[5] Fujiwara H. et al , "A Study on Subsurface Structure Model for Deep Sedimentary Layers of Japan for Strong-motion Evaluation," Technical Note of the National Research Institute for Earth Science and Disaster Prevention, No.337, 2009 (in Japanese).

[6] Hasegawa M. and Nakai S., "A study on effective input motions of pile foundations," Journal of structural and construction engineering, No.422, pp.101-115, Architectural Institute of Japan, 1991 (in Japanese).

[7] Konagai, K., Yin, Y. and Murono, Y., "Single beam analogy for describing soil-pile group interaction," Soil Dynamics and earthquake Engineering, 23(3), 213-221, 2003.

[8] Tajimi H., “A Contribution to Theoretical Prediction of Dynamic Stiffness Surface foundation," Proc. of 7th World Conference on Earthquake Engineering, Vol.5, pp.105-112, 1980. 